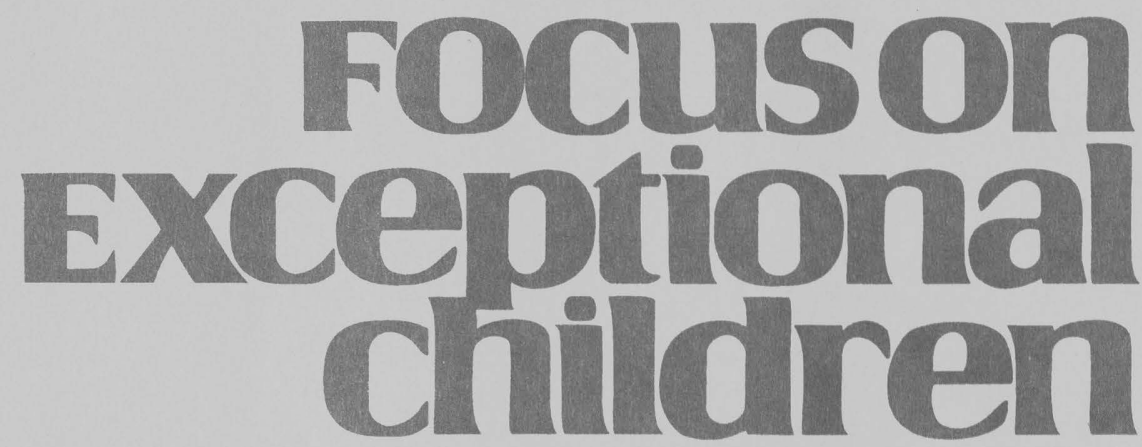

\title{
Personalized Grading Plans: \\ A Systematic Approach to Making the Grades of Included Students More Accurate and Meaningful
}

\author{
Dennis D. Munk and William D. Bursuck
}

Tommy is a fifth grader with a learning disability that severely affects his ability to organize and write responses to questions. He has just received his first report card grades since being included in the general education social studies class. Tommy's teachers made several instructional adaptations for him, including providing him with study guides prior to tests. As he glances over his grades, Tommy is crestfallen to see the D in the social studies box. He knew he had not done well on the longer written tests in class, but he had worked hard to prepare, and he had attended regularly and completed all of his homework and in-class projects. What else could he do?

Samantha is a seventh grader with a learning disability that affects her reading and organizational skills. She is both excited and nervous as she receives her report card. Samantha is most concerned about her math grade, so she is surprised to see that she received a $C$ - in science, a class she felt good about and in which the instructor seemed to treat her like all of the other kids. The class had worked in cooperative learning groups the entire semester, and Samantha's group had worked well together. Their project on the causes and effects of erosion was interesting, and Samantha had learned a lot. Unfortunately, the project was only a part of her grade and the group work was not counted toward that grade. Other assignments that required extensive reading and summarization were difficult for her, and Samantha knew she had not done as well on those.

\footnotetext{
Dennis Munk is an associate professor and William Bursuck a professor in the department of teaching and learning at Northern Illinois University in DeKalb, Illinois. They are the co-directors of Project PRIDE at Northern Illinois University, where Dennis Munk serves as project associate and William Bursuck serves as principal investigator.
} 
How unusual are the experiences of Tommy and Samantha? Do seemingly motivated students with learning disabilities work hard in general education classes only to receive lower grades than their peers? Donahoe and Zigmond (1990) found that $60-70 \%$ of students with learning disabilities passed their mainstreaming classes but received a belowaverage (below a $\mathrm{C}-$ ) grade. A similar finding was reported by Valdes, Williamson, and Wagner (1990), whose survey results indicated that $60 \%$ of secondary students with learning disabilities had grade point averages (GPAs) of 2.24 or lower and 35\% had GPAs below 1.74 (below a $\mathrm{C}-$ ). In addition, at least one third of the students surveyed had received at least one failing grade. More recently, Wagner, Blackorby, and Hebbeler (1993; cited in U.S. Department of Education, 1994) reported that a nationwide sample of students with learning disabilities in grades 9-12 had an average cumulative GPA of 2.3; of particular concern was the performance of 9th and 10th graders, whose average GPAs were 1.9. In a study comparing outcomes for middle school students with learning disabilities in an inclusive setting (36 students) versus a pullout model (22 students), Rea, McLaughlin, and

\section{Focuson
Exceptional
childiren}

ISSN 0015-511X

FOCUS ON EXCEPTIONAL CHILDREN (USPS 203-360) is published monthly except June, July, and August as a service to teachers, special educators, curriculum specialists, administrators, and those concerned with the special education of exceptional children. This publication is annotated and indexed by the ERIC Clearinghouse on Handicapped and Gifted Children for publication in the monthly Current Index to Journals in Education (CIJE) and the quarterly index, Exceptional Children Education Resources (ECER). The full text of Focus on Exceptional Children is also available in the electronic versions of the Education Index. It is also available in microfilm from Xerox University Microfilms, Ann Arbor, MI. Subscription rates: individual, \$36 per year; institutions, \$48 per year. Copyright (C) 2004, Love Publishing Company. All rights reserved. Reproduction in whole or part without written permission is prohibited. Printed in the United States of America. Periodical postage is paid at Denver, Colorado. POSTMASTER: Send address changes to:

$$
\begin{gathered}
\text { Love Publishing Company } \\
\text { Executive and Editorial Office } \\
\text { P.O. Box } 22353 \\
\text { Denver, Colorado } 80222 \\
\text { Telephone (303) 221-7333 }
\end{gathered}
$$

\section{EDITORIAL BOARD}

Edwin Ellis

University of Alabama
Tim Lewis

University of Missouri

\section{Chriss-Walther Thomas}

University of Kansas

Susan T. Warhover Editor
Stanley F. Love Publisher
Walther-Thomas (2002) reported the average report card grades in the core subjects (language arts, math, science, and social studies). Grades for students receiving inclusive support ranged from 2.3 to 2.6 for the core courses, while those in the pullout model ranged from 1.6 to 1.8 for the core courses. Although findings in this study suggest the potential for students to receive passing grades in general education classes, they are consistent with previous studies indicating that students with disabilities are at increased risk for low or failing grades in general education classes.

Although research findings suggest relatively poor outcomes under traditional grading practices, individualization of the grading system for students with disabilities, through use of grading adaptations, may serve to alleviate this problem (Munk, 2003; Munk \& Bursuck, 2001, 2005). Grading adaptations are not a new idea, as evidenced by the fact that $50 \%$ of general education teachers report using them on an informal basis (Bursuck et al., 1996), and as many as 60\% of school grading policies include stipulations for adapting the grades of students with disabilities (Polloway et al., 1994). Despite their apparent appeal to teachers, grading adaptations must be implemented thoughtfully and systematically, especially in general education settings where recommended grading practices emphasize progress on learning standards, quality of summative assessments, and exclusion of student effort (Marzano, 2000; O'Connor, 2002; Guskey \& Bailey, 2001). Fortunately, grading adaptations can be used in a manner that increases access to the general curriculum and avoids the perception that adaptations just make it easier for a student to earn a higher grade. The purpose of this article is to describe issues related to the use of grading adaptations and procedures for a model that develops personalized grading plans (PGPs) that has been used to guide teams in implementing grading adaptations in a systematic manner that enhances perceived accuracy, validity, and fairness of the adaptations (Munk, 2003; Munk \& Bursuck, 2001, 2005).

\section{KEY GRADING ISSUES}

When selecting grading adaptations for individual students, a number of key issues need to be considered. These involve the purposes of grades, options for adapting grades, the relationship of grading adaptations to district grading policies, the impact of grading adaptations on transitions to school and work, the interface of grading adaptations with instructional and curricular adaptations, and the acceptability of grading adaptations to teachers and students.

\section{Purposes of Grading}

Letter grades (i.e., A-F) are so ingrained in our image of school, due in part to the fact that as many as $80 \%$ of schools 
require letter grades (Polloway et al., 1994), that it is easy to overlook the multitude of meanings or purposes that may be assigned to grades. Educators may have one purpose for grades (e.g., to indicate student performance relative to other students), while parents may feel the grades have a somewhat different purpose (e.g., to indicate how hard their children tried), and students may ascribe yet another purpose (e.g., to indicate that they passed their course and received credit toward graduation). In light of the different meanings attributed to grades, the process of considering the need for and type of an adaptation to report card grades must begin with discussion of the purpose of a grade. Figure 1 presents an overview of commonly cited purposes for grades (Bradley \& Calvin, 1998; Carpenter, 1985; Ornstein, 1994) phrased as questions that educators, parents, and students may ask themselves when identifying a purpose for grades.

A process for identifying and implementing grading adaptations is presented later in this article. The first step involves the educational staff, parents, and the student reaching agreement on the purposes of a grade. Such agreement may be difficult to achieve given the rigidity of current

When I give a grade, review a grade, or receive a grade, do I expect the grade to

- communicate general achievement and quality of work on school curriculum?

- communicate effort and work habits?

- motivate student/me to keep working?

- communicate progress on individual goals or mastery of specific content?

- communicate how child's/my performance compares to that of other students?

- communicate strengths and needs, and provide feedback on how to improve?

- provide direction for planning for future, afterschool life?

- provide information to teachers for planning instruction?

- convey abilities to postsecondary schools or employers?

- provide information to teachers about which students may need special help or programs?

FIGURE 1

Questions for Identifying the Purpose of a Report Card Grade grading schemes as well as the lack of involvement parents and students have historically enjoyed in the grading process. Still, while time-consuming, this initial step may be the most informative of all of the steps in the process and can result in the team agreeing to find ways to make report card grades meet multiple purposes.

\section{Grading Adaptation Options}

Table 1 presents an overview of grading adaptations, with potential advantages and disadvantages described for each. Several types of adaptations are covered, including changing grading criteria (e.g., varying the weight of assignments, modifying curricular expectations for graded work, developing an individualized contract with the student, grading on the basis of improvement), providing supplemental information to letter and number grades (e.g., adding written comments, adding information from the student activity log, adding information from portfolios or performance-based assessments), and using alternatives to letter and number grades (e.g., using pass-fail grades, using competency checklists). It is important to note that not all of these adaptations have been empirically validated, although the perceived acceptability of specific adaptations to teachers and students has been investigated as will be discussed later. At this time, the authors are concluding a three-year, grantfunded project involving personalized grading plans for students with disabilities in inclusive middle school classrooms. Participating teams of teachers, parents, and student selected from the following menu of grading adaptations: (a) basing the grade on performance on prioritized content and related assignments, (b) incorporating strategy use into grading criteria for individual assignments, (c) incorporating progress on individualized education program (IEP) objectives into grades for individual assignments or the overall grade for the marking period, (d) basing part of a student's grade on effort or improvement, or (e) changing the weights that assignments count toward a final grade. A more detailed description of the potential benefits for each type of adaptation, as well as tools and procedures for implementation, can be found in the book Solving the Grading Puzzle for Students With Disabilities (Munk, 2003).

\section{District Grading Policies}

Polloway et al. (1994), in a nationwide survey of 225 school districts, found that $65 \%$ of the districts had written grading policies; of those districts having written grading policies, $60 \%$ included some guidelines for adapting grades for students with disabilities. When we reviewed the grading policies of several school districts, we found significant variation in the conditions under which an adaptation might be warranted, the process for selecting and documenting an adaptation, and the process for receiving approval for the 


\title{
TABLE 1 \\ Overview of Grading Adaptations
}

\begin{abstract}
Adaptation
Adaptations That Involve Changing Grading Criteria

Vary weighting of assign- Vary how much certain ments.

\section{assignments count toward grade.}

Modify curricular expectations for graded work.

Develop individualized contract with student.

\begin{abstract}
Grade on basis of improvement.
\end{abstract}

Prioritize specific curriculum to be used to determine grade.

Teacher and student agree on quality, quantity, and timeliness for work completion.

Assign extra points toward final grade for improvement in achievement or effort since last marking period.

\section{Supplemental Information to Letter and Number Grades}

Add written comments.

Add information from student activity log.

Add information from portfolios and/or performance-based assessment.
Add comments on products, performances, and other criteria used to determine final grade.

Maintain daily notes or ratings of student performance in specific areas.

Collect and summarize student work that reflects student effort, progress, and achievement.
Example

Increase proportion of performance on in-class

Write on individualized education program (IEP) that grading in geography will be based on research on Wisconsin while rest of class covers entire region.

Contract indicates that student will receive an A-for completing all assignments at $80 \%$ accuracy, attending all classes, and completing one extra-credit report.

Change a $C$ to $a$ B if student's total points were significantly higher than for prior marking period. final grade determined by science experiments.
Write on report card or attachment that grade reflects performance on combination of IEP objectives and other class requirements.

State on student's report card that while the stu-dent's grade was the same this period, daily records indicate improvement in completing assignments on time.

State on report card that student's written language showed an increase in word variety, sentence length, and quality of ideas.

\section{Advantages}

Ease of implementation; assignments can be tailored to student abilities.

Ease of implementation; requires no change to curriculum.

Can be tailored to student strengths; student has input; may include classwide assignments.

Reflects change in performance; may motivate student; requires no change to curriculum.

Provides more detailed information to parents and student; may indicate areas for improvement.

Provides more detailed information to parents and student; may indicate areas for improvement.

Provides detailed information to parents and student; may indicate areas for improvement; may draw attention to student strengths.

Give student a "pass" for completing $80 \%$ of daily work with at least $65 \%$ accuracy and attending at least $90 \%$ of classes.

Attach a checklist to report card indicating that during the last quarter the student mastered addition facts, 2-digit addition with regrouping, and counting change to $\$ 1.00$.
Establishes clear criteria for student to follow; reduces emphasis on letter grades.

Provides detailed information on content mastered and remaining; based on actual curriculum.
All assignments may be equal in difficulty; may require extra time for teacher.

Important content may be excluded; may require individualized assessment.

Requires judgment due to lack of standards; student may not be given input; may require individualized assignments.

Required amount of change requires judgment; requires separate record keeping.

Policy may prevent writing on report card (teachers should check policy before marking report card).

Policy may prevent writing on report card; maintaining daily log may be time-consuming.

Determining products to collect requires judgment; products may be difficult to summarize; assembling portfolio may be time-consuming.

Postsecondary programs and colleges may require letter grades on transcripts.

Postsecondary programs or colleges may require letter grades on transcripts. 
use of an adaptation. Because of the variation that exists in grading policies, we recommend that prior to selecting a grading adaptation, the team consult the school district grading policy, if there is such a policy.

Adaptations that involve changing grading criteriaincluding varying the weight of assignments, modifying curricular expectations, using contracts and modified course syllabi, and grading on improvement-are most consistent with practice in inclusive settings and are therefore less likely to require special approvals or consideration. Such adaptations should be documented in a student's IEP. Prior to adding a grading adaptation to an IEP, however, it is important to determine if the adaptation overlaps with instructional and curricular adaptations already required by the IEP. Effective use of instructional and curricular adaptations may mitigate the need for a grading adaptation, and the distinction between types of adaptations suggested and required should be clarified prior to implementing a grading adaptation. Only grading adaptations that do not overlap with present IEP components should be added.

Another policy concern involves how teachers may indicate that a student is receiving adapted grades. Legal guidelines regarding what can or should be marked on a temporary or permanent report card vary among states, and districts should be aware of their state's regulations before placing any additional information on a student's report card. Grading policies among districts also vary considerably; before implementing an adaptation, educators should consult their district and statewide policies.

\section{Future Transitions to School and Work}

Often, the motivation for making grading adaptations is to enhance the quality of feedback provided to educators, parents, and students. However, one must also keep an eye on the future if alternatives to letter/number grades, such as pass-fail grades and competency checklists, are used. High schools rely almost exclusively on letter/number grades for calculating GPA and class rank, both of which are used for college admissions. In addition, training programs and colleges may not grant credit to classes in which an alternative grade was given. Before choosing these adaptations, the team should consider the student's postsecondary plans, perhaps as part of the regular transition planning process. If the student plans to attend a particular postsecondary program or institution, contacts should be made to determine how alternatives to letter/number grades will affect admission or scholarship status.

\section{Interface With Instructional and Curricular Adaptations}

Considerable attention has been given to instructional and curricular adaptations, or adapted instruction, for students with disabilities included in general education classes (e.g., Friend \& Bursuck, 1999; Fuchs, Fuchs, Hamlett, Phillips, \& Karns, 1995; Keogh, 1988; Schumm \& Vaughn, 1995; Zigmond \& Baker, 1994). The resulting body of literature suggests adaptations in the areas of classroom organization (e.g., placing a student's desk in close proximity to the teacher, implementing an individualized behavior contract for class transitions); classroom grouping (e.g., using small-group rather than large-group instruction, adopting peer tutoring to provide extra practice); instructional materials (e.g., using taped textbooks, making study guides to accompany readings, using assistive technology); instructional methods (e.g., providing extra teacher-directed instruction, using hands-on experiments and multimedia presentations, assigning fewer homework problems); and evaluation (giving oral tests, allowing extended time on tests, using individualized grading contracts). The use of these adaptations may obviate the need for grading adaptations, as is the case with the following two scenarios.

In one scenario, the aforementioned adaptations or methods are implemented classwide, with all students participating in very similar activities and producing like performances and products. For example, a science teacher may use hands-on experiments to enhance the motivation and performance of all students, including those with disabilities who struggle with comprehending dense texts and memorizing technical terms. In such a situation, students with and without disabilities may be graded on the same criteria. There would be an underlying assumption that the instructional methods used had effectively equalized expectations and facilitated success for students with disabilities.

In an alternative scenario, individual adaptations may be made for one or more students with disabilities while no attempt is made to adapt the classwide methods being used. For example, in the science class just mentioned, students with learning disabilities in written expression may be allowed to make oral lab reports. In this situation, the individual adaptations would be intended to equalize the expectations, and students with disabilities would still be graded according to the classwide criteria.

If we assume that the general and special educators in the scenarios just described collaborated to provide the best possible learning environment for students with disabilities, then can we also assume that those students will receive the grades they "deserve" and that the grades will serve their intended purpose? A firm and confident response to this question is often difficult, because no clear criterion for making such a judgment exists. Further complication may occur because of differing interpretations of guidelines requiring schools to provide adequate, if not optimal, conditions for student success. In the absence of a clear criterion for determining when instructional and curricular 
adaptations have been properly selected, implemented, and monitored, we cannot judge when it is appropriate to grade a student based on classwide criteria or when a grading adaptation would be helpful. The matter is further complicated by the likelihood that some students who do receive exemplary instruction and support will still receive relatively low grades. Thus, while the type and extent of instructional adaptations being used and the resulting grade are important pieces of evidence when considering the need for a grading adaptation, these factors may not be as important as the purposes for grading identified by the team in the first place. Indeed, even low grades may communicate accurate and helpful information, though perhaps to the detriment of student effort and self-efficacy.

\section{Teachers' and Students' Perceptions of Grading Adaptations}

In the absence of empirically validated standards for determining the need for a grading adaptation or for matching a particular adaptation to student characteristics, additional factors, such as the perceived acceptability of specific adaptations, may inform a decision to make an adaptation. Perceived acceptability of a grading adaptation can be defined as the extent to which teachers find the adaptation helpful in accurately describing a student's performance (Polloway, Bursuck, Jayanthi, Epstein, \& Nelson, 1996). When Bursuck and colleagues (1996) surveyed 368 elementary and secondary general education teachers on the use and utility of grading practices and adaptations, the results indicated that while number and letter grades were most commonly used, teachers found the less often used adaptations of pass-fail grades, checklists, and written comments actually more helpful for students with disabilities. However, the teachers indicated that letter and number grades could be adapted for students with disabilities by (in descending order of perceived helpfulness) (a) basing grades on process instead of product, (b) basing grades on amount of improvement, (c) basing grades on progress on IEP objectives, (d) adjusting grade weights based on assignment and ability, and (e) basing grades on criteria met in an individual contract. Adaptations the teachers rated as less helpful were basing grades on less content, using a modified grading scale, assigning a passing grade for effort, or assigning a passing grade no matter what.

Evidence that teachers consider grading adaptations an appropriate and viable strategy for improving the accuracy and purposefulness of grades is found in the fact that $50 \%$ of the teachers in the study by Bursuck et al. (1996) reported that they had used specific grading adaptations for students without disabilities. Thus, adapting grades is not considered solely an intervention for special education students.
An explanation for teacher preferences for specific grading adaptations may be student preference; teachers may be unlikely to use adaptations that are perceived negatively by their students (Schumm \& Vaughn, 1995). A study by Bursuck, Munk, and Olson (1999) sheds light on student preferences in this regard. The researchers surveyed 275 high school students, including 15 with learning disabilities, about the fairness of nine commonly used grading adaptations. For each of these adaptations, students were asked whether they thought making the adaptation for some students in class but not for other students in the class was fair. For each one, a majority or better of the students felt that making the adaptation for some students but not others was unfair, although significant variation in responses was evidenced across the various adaptations. Students thought that raising grades when students tried their hardest and giving two grades, one for effort and one for achievement or quality of product, were the most fair adaptations. The adaptations that students thought were least fair included changing grading weights, using a different grading scale, and passing students no matter what. A majority also thought that grades in more difficult classes should count more toward overall GPA. The students believed that a grading system should treat everyone equally; therefore, they felt that any adaptation made available to only certain students was unfair.

Perhaps not surprisingly, students with disabilities viewed at least two of the adaptations more favorably than did their peers without disabilities. Two thirds of the students with disabilities thought it was fair to grade some students using a different scale and to have grades count the same toward GPAs regardless of the difficulty of the class.

Educators looking to student and teacher perceptions for guidance in selecting an adaptation might draw several conclusions. First, the use of adaptations seems to be acceptable to teachers, who report using them with students with and without disabilities. However, students without disabilities think that using adaptations for some, but not all, students is unfair. Thus, some teachers may be reluctant to use adaptations that cannot be applied classwide, such as changes made for tracking IEP objectives and alternatives to letter and number grades. Teachers may be particularly reticent to make individualized adaptations for students with learning disabilities whose differences are not obvious and who are not likely to require an alternative curriculum. Second, teachers and students seem to be sensitive to the impact of grades on the motivation of students with disabilities, a purpose for grading listed in Figure 1. Encouraging news is that adaptations that could have a positive effect on student motivation, such as grading on the basis of improvement, weighting assignments, and grading on effort and achievement, were considered by teachers and students to be more fair. A third theme is found in the overwhelming perception 
that passing students no matter what they do is unfair and will discourage effort by those students as well as their peers. Finally, the perceptions of teachers and students seem to reinforce the overarching need for implementing a grading adaptation only when a mutually agreed-upon purpose is identified by the teacher, parent, and student. This important step, along with others in a potential process for implementing a grading adaptation, is presented next.

\section{PROPOSED PROCESS FOR MAKING GRADING ADAPTATIONS}

Obviously, the decision to implement a grading adaptation involves a considerable degree of professional and parental judgment. We have recently completed a research project involving the PGP process for implementing grading adaptations for students with disabilities (Munk \& Bursuck, 2005). Our model is outlined in Figure 2.

The first two steps involve the identification of purposes for grading. We recommend that teachers spend time prior to the first meeting with the parents and student developing a clear sense of the purposes that grades may have, including identifying specific examples for each. The teacher can then clearly explain the grading purposes listed in Figure 1 to the parents and student at the beginning of the first meeting and encourage the parents and student to ask for additional examples or clarification. Once the potential purposes for grades have been discussed, each participant should take several minutes to write down the purposes he or she perceives for grades. After everyone has had the opportunity to generate one or more purposes, the teacher should record everyone's responses and begin the process (Step 3) of selecting, by weighting or ranking, 2-3 purposes that the group will use to guide the selection of an adaptation.

Once the first three steps are completed, the team should proceed to Step 4, in which they identify, discuss, and compare the learner's characteristics and the classroom demands (i.e., assignments, activities, behavioral expectations). The discussion should begin with a review of the class requirements and demands that will contribute to the course grade. The discussion can be expedited if the teacher has already completed a worksheet that includes demands (assignments, activities, behavioral expectations) for the marking period and indicates how much weight each will have in computing the final grade. Next, the team should compare the student's characteristics to the course demands and grading system and project how the interaction of the demands and learner characteristics will affect the student's course grade. Although the teacher should retain a facilitator's role in this step, it is important that the discussion not be centered around standardized testing results, as might be the case in a multidisciplinary conference. Rather, this discussion
Step 1: Clarify teacher purposes for grades (i.e., the information the grade should convey).

Step 2: Clarify parent and student purposes for grades (i.e., the information parents and students want to receive).

Step 3: $\quad$ Arrive at mutually agreed-upon purpose(s) for grades.

Step 4: Examine student learning characteristics (achievement level, impact of disability, areas of strength, limitations) and classroom demands that will contribute to the student's grade. Identify potential grading problems (learner characteristics interacting with class requirements and grading system).

Step 5: Review current grading system and determine if grade could be higher and/or more meaningful if a grading adaptation was implemented.

Step 6: Select an adaptation that meets agreedupon purposes and addresses the grading problems identified previously.

Step 7: Document the adaptation in the individualized education program and begin implementation.

Step 8: Monitor the effectiveness of the adaptation (i.e., does it meet the purposes identified?).

\section{FIGURE 2 \\ Protocol for Implementing a Grading Adaptation}

should be frank and should center around the requirements for the class (e.g., tests, in-class assignments, homework) and how the student's disability causes him or her to be more or less successful on these requirements. The outcome of this step should be a list of activities on which the student is most successful and a list of those activities that exacerbate the student's limitations. This discussion may include a brief review of existing curricular and instructional adaptations. For example, the team might conclude that a student's algebra grade is low not because the student is unable to solve complex equations but because he or she has problems remembering math facts, which is causing lower test scores and hence lower grades. The team might then decide that giving the student a calculator to use when problem solving may eliminate the need for a grading adaptation. 
Step 5 involves a review of the current grading system for the class. Having already highlighted classroom demands that may interact with the student's characteristics to produce more or less success, the team would be prepared to project the student's grade for the course. Two questions can be used to establish the need for a grading adaptation: (a) Could the student's grade be higher if a grading adaptation were implemented?, and (b) Could the student's grade be more meaningful (meet the desired purposes) if a grading adaptation were implemented? A positive response to either question would prompt the team to enter Step 6, which involves the selection of an adaptation. Step 6 begins with a review of the types of grading adaptations and identification of one or more adaptations that would address student characteristics and meet the purposes for grading identified in Step 3. Here again, the teacher should prepare ahead of time by becoming familiar with each adaptation and developing examples for parents and students. Once an adaptation is identified, an addendum to the IEP describing that adaptation should be written and attached to the IEP (Step 7). Finally, before the team meeting is adjourned, the participants should pinpoint expected grading outcomes and agree to a timeline for reviewing the effectiveness of the adaptations (Step 8). As evaluation will be ongoing, this step should involve periodic written communication between the teacher and the parents.

It should be obvious by now that parents and students would be active participants in the protocol, a role for which they may be neither accustomed nor prepared. In general, team meetings will be more productive if parents are made to feel welcome, their perceptions and concerns are carefully considered, they are treated as important, and professionals work with them to address student needs (Friend \& Bursuck, 1999). More specifically, parents may feel more comfortable.if, as suggested in the protocol, they are allowed to identify the purposes they feel grades should have before being asked to participate in a discussion of adaptations. Educators should also provide parents and students with clear, nontechnical information about the school's grading policy and potential adaptations. As students are not accustomed to participating in decisions regarding their grades, they will likely benefit from receiving concrete examples of how adaptations would affect their assignments and grades in a specific class. Students may also benefit from direct instruction in how to contribute to a team meeting (see Van Reusen and Bos, 1994, for a specific strategy).

Because we are still in the process of investigating this protocol for identifying and implementing a grading adaptation, we can only hypothesize what will transpire when a team meets to begin the process. The following is one possible scenario involving Samantha, one of the students profiled at the beginning of this article, her parents, and her teachers.

\section{A GRADING ADAPTATION FOR SAMANTHA}

Both Samantha and her parents were disappointed with the C-Samantha received in science and felt that the grade was unfair because Samantha liked the class and had always received positive feedback from the general and special education teachers. Following a call to Mrs. Stoneman, the science teacher, a meeting was scheduled to discuss the possibility of using a grading adaptation for the next marking period. Mrs. Simon, the special educator, prepared a "reader-friendly" handout on the grading adaptations that were allowed under the school's grading policy. When the team met, Mrs. Simon opened the meeting by reviewing the list of purposes for grades. Then, each person took 5 minutes to prioritize the purposes from most to least important. Each team member then shared his or her list with the group.

Not surprisingly, differences existed in the lists. Samantha thought her grade should indicate how hard she had worked because she did everything her teachers had requested. Her parents had a similar view; however, Samantha's father also thought that he should be able to ascertain from a grade how much of the material Samantha had mastered and what she needed to improve on. Both parents gave a high ranking to the importance of a grade communicating the probability that Samantha would be able to go on to college. Mrs. Simon indicated that grades should serve many purposes, with the most important being communicating achievement and measuring effort. Mrs. Stoneman added that grades are usually used to provide information on how a student's performance compares with that of other students, although she did not necessarily agree with that emphasis. After an enlightening discussion, the team agreed that the most important purpose of Samantha's grade in science should be to measure effort and communicate the quality of her work.

Mrs. Stoneman then led the team through a review of Samantha's learning characteristics and the demands of the science class. This was accomplished by writing Samantha's strengths and limits on a large sheet of poster board and then outlining the class demands on a second piece of poster board. By comparing the two boards, the team could quickly see that Samantha's limits in responding to timed, written production test items would interact with the exams for the class, which involved several open-ended questions requiring students to integrate and summarize multiple concepts and write clearly and quickly.

Having identified the potentially negative interaction between Samantha's learning characteristics and their likely effect on her grade, the team responded to the questions 
"Could Samantha's grade be higher" and "Could Samantha's grade be more meaningful?" with a unanimous yes. Everyone agreed that the $\mathrm{C}$ - she had received was unsatisfactory because it was so heavily influenced by just three inclass exams rather than taking into account her day-to-day performance in group work and on exercises completed when reading.

Thus, the team reviewed the possible adaptations and reached consensus that a grading adaptation involving an individual contract was desirable, because the contract could include measures of effort, such as questions asked during class, attendance, and preparation, as well as formal projects and assignments. Furthermore, the contract would allow Samantha's parents to monitor her performance in each area and to determine areas in which they might help her when needed.

Mrs. Simon and Samantha wrote the contract, which indicated that Samantha's grade would be based on the following performances or activities: completion of reading guides prior to class, participation (questioning, explaining, note-taking) during cooperative learning group activities and projects, and word-processed responses to reading questions. Criteria for accuracy and timeliness were established for each type of assignment. Both Samantha and her parents recognized that Samantha's workload would not be reduced but rather would be prioritized so as to take advantage of her strengths and motivation to succeed. The team agreed to meet again halfway through the marking period to assess the effectiveness of their choice. An example of what Samantha's grading contract might look like is presented in Figure 3.

\section{SUMMARY}

The practice of making grading adaptations is certainly not new. For years, teachers have made informal adaptations based on student characteristics and classroom requirements. Interest in a more systematic approach to making adaptations has no doubt been sparked by the increase in the number of students with disabilities, particularly learning disabilities, being included in general education classes.

The purpose of this article was to provide an overview of the types of grading adaptations and to discuss the factors that might influence the selection of a particular adaptation. A protocol that has been field-tested was described, with the caveat that educators should be prepared for a variety of responses from parents and students about the purposes of grades. Indeed, the step of identifying the purpose(s) of a grade promises to be enlightening.

Regarding the grading adaptations themselves, several findings from the fairness research may be useful. Teachers interested in implementing grading adaptations only for students with disabilities might expect some protest from other students. Future research might address the effects of informing general education students about the rationale for grading adaptations on student perceptions of fairness. The importance of using grades to acknowledge effort and improvement by students for whom school is difficult is also evident. Adaptations that involve giving two grades, one for effort and one for achievement, or that involve varying grading weights are perceived by students as more fair and may have a positive impact on student motivation to succeed. Such adaptations are also attractive in that they require relatively less effort by the teacher and communicate more information about the student's performance. We hope that research on the relative effectiveness of specific adaptations will become available. Until that time, the protocol for making grading adaptations will be built primarily upon the cooperation and judgment of teachers, parents, and students.

\section{REFERENCES}

Bradley, D. F., \& Calvin, M. B. (1998). Grading modified assignments: Equity or compromise? Teaching Exceptional Children, 3I(2), 24-29.

Bursuck, W. D., Munk, D. D., \& Olson, M. (1999). The fairness of report card grading adaptations: What do students with and without disabilities think? Remedial and Special Education, 20(2), 84-92.

Bursuck, W. D., Polloway, E. A., Plante, L., Epstein, M. H., Jayanthi, M., \& McConeghy, J. (1996). Report card grading and adaptations: A national survey of classroom practices. Exceptional Children, 62, 301-318.

Carpenter, D. (1985). Grading handicapped pupils: Review and position statement. Remedial and Special Education, 6(4), 54-59.

Donahoe, K., \& Zigmond, N. (1990). Academic grades of ninth-grade urban learning disabled students and low-achieving peers. Exceptionality, 1, 17-27.

Friend, M., \& Bursuck, W. D. (1999). Including students with special needs: A practical guide for teachers (2nd ed.). Boston: Allyn \& Bacon.

Fuchs, L. S., Fuchs, D., Hamlett, C. L., Phillips, N. B., \& Karns, K. (1995). General educator's specialized adaptation for students with learning disabilities. Exceptional Children, 61, 440-459.

Guskey, T. R., \& Bailey, J. M. (2001). Developing grading and reporting systems for student learning. Thousand Oaks, CA: Corwin Press.

Keogh, B. K. (1988). Improving services for problem learners: Rethinking and restructuring. Journal of Learning Disabilities, 21, 19-22.

Marzano, R. J. (2000). Transforming classroom grading. Alexandria, VA: Association for Supervision and Curricular Development.

Munk, D. D. (2003). Solving the grading puzzle for students with disabilities. Whitefish Bay, WI: Knowledge by Design, Inc.

Munk, D., \& Bursuck, W. D. (2001). What report card grades should and do communicate: Perceptions of parents of secondary students with and without disabilities. Remedial and Special Education, 22, 280-286.

Munk, D. D., \& Bursuck, W. D. (2005). Personalized grading plans for students with disabilities. Manuscript in preparation.

O'Connor, K. (2002). How to grade for learning: Linking grades to standards. Glenview, IL: Pearson Skylight.

Ornstein, A. C. (1994). Grading practices and policies: An overview and some suggestions. NASSP Bulletin, 78(561), 55-64. 
A report card grade for the third marking period (12 weeks) will be based on the following assignments:

1. Reading Guides: Samantha will receive a study guide from her science teacher each time a reading assignment is given. Reading assignments will be given 2 days per week. Each guide will include questions about the reading and may include simple activities or experiments. Each guide will be worth 10 points. Points will be deducted for incorrect or missing answers. Incorrect answers can be corrected by the next class to earn back $1 / 2$ point.

2. Participation in Group Activities/Experiments: Samantha will participate in group activities or experiments 2 days per week. Each of those days she will earn 0-10 points for fulfilling her role as notetaker, questioner, or summarizer. Roles will be assigned by her teacher. Samantha will receive daily feedback on a checklist that includes the responsibilities for each of the three roles. Points will be deducted when Samantha is not prepared for her role or does not pay attention during the activity.

3. Answers to Essay Questions Using a Word Processor: At the end of each of the four chapters in the text, Samantha will complete three essay questions that require summarization and synthesis of information covered by the text and in class. She will outline her answers to these questions while other students take the chapter test. She will complete her answers during her free period and at home using a word-processing program. The teacher will assign a due date. Each of the four sets of questions will be worth 40 points.

A report card grade will be based on the following criteria:

Study Guides: 12 weeks $\times 2$ guides per week $\times 10$ points each $=240$ points

Participation Grades: 12 weeks $\times 2$ grades per week $\times 10$ points each $=240$ points

Essay Questions: 4 chapters $\times 40$ points each $=160$ points

Total $=640$ points

Grading Scale:

$576-640$ points $=$ A

$512-575$ points $=B$

$448-511$ points $=C$

$384-447$ points $=\mathrm{D}$

383 or below $=F$

Signatures

Samantha

Parents

Special Educator

Science Teacher

Principal

Guidance Counselor 
Polloway, E. A., Bursuck, W. D., Jayanthi, M., Epstein, M. H., \& Nelson, J. S. (1996). Treatment acceptability: Determining appropriate interventions within inclusive classrooms. Intervention in School and Clinic, 31, 133-144.

Polloway, E. A., Epstein, M. H., Bursuck, W. D., Roderique, T. W., McConeghy, J., \& Jayanthi, M. (1994). Classroom grading: A national survey of policies. Remedial and Special Education, 15(3), 162-170.

Rea, P. J., McLaughlin, V. L., \& Walther-Thomas, C. (2002). Outcomes for students with learning disabilities in inclusive and pullout programs. Exceptional Children, 68(2), 203-222.

Schumm, J. S., \& Vaughn, S. (1995). Getting ready for inclusion: Is the stage set? LD Research and Practice, 10, 169-179.
U.S. Department of Education. (1994). Sixteenth annual report to Congress on the implementation of the Individuals With Disabilities Education Act. Washington, DC: Author.

Valdes, K. A., Williamson, C. L., \& Wagner, M. M. (1990). The national longitudinal study of special education students (Vol. 1). Menlo Park, CA: SRI International.

Van Reusen, A., \& Bos, C. S. (1994). Facilitating student participation in individualized education programs through motivation strategy instruction. Exceptional Children, 60, 466-475.

Zigmond, N., \& Baker, J. (1994). Is the mainstream a more appropriate educational setting for Randy? A case study of one student with learning disabilities. LD Research and Practice, 9, 108-117. 


\section{INDEX ・ Volume 36}

\section{Author Index}

Bursuck, William D. (May 2004)

Denti, Lou (March 2004)

Feldman, Kevin (March 2004)

French, Nancy K. (October 2003)

Hawkins, Annie (January 2004)

Johnson, Lawrence J. (January 2004)

Livneh, Hanock (February 2004)

Matson, Shannon L. (December 2003)

Munk, Dennis D. (May 2004)

Pugach, Marleen C. (January 2004)

Pullo, Robert E. (February 2004)

Rynders, John E. (December 2003)

Schleien, Stuart J. (December 2003)

Scott, Terrance M. (September 2003)

Spagna, Michael E. (April 2004)

Tarver-Behring, Shari (April 2004)

VanTassel-Baska, Joyce (November 2003)

Wilson, Lisa M. (February 2004)

\section{Chronological Index of Titles}

Making Behavior Intervention Planning Decisions in a Schoolwide System of Positive Behavior Support (September 2003)

Paraeducators in Special Education Programs (October 2003)

Selecting Instructional Strategies for Gifted Learners (November 2003)

Transition for Children With Down Syndrome From School to Community (December 2003)

School-Family Collaboration: A Partnership (January 2004)

Group Counseling for People With Physical Disabilities (February 2004)

High-Access Instruction: Practical Strategies to Increase Active Learning in Diverse Classrooms (March 2004)

Counseling With Exceptional Children (April 2004)

Personalized Grading Plans: A Systematic Approach to Making the Grades of Included Students More Accurate and Meaningful (May 2004) 